\author{
Hemn Muhammed Mustafa ${ }^{1 \star}$, Hadi \\ Muhamad $^{2}$ and Araz Abdulfaraj ${ }^{2}$ \\ ${ }^{1}$ Department of medicine, Shar teaching hospital, \\ Sulaimani, kurdistan / Iraq \\ ${ }^{2}$ Internal medicine board candidate, SHO
}

Dates: Received: 08 April, 2015; Accepted: 12 May, 2015; Published: 14 May, 2015

*Corresponding author: Dr. Hemn Muhammed Mustafa, MD, FIBMS [med], MB, ChB, Department of medicine, Shar teaching hospital, Sulaimani, kurdistan / Iraq, E-mail: hemn1979hemn@yahoo.com

www.peertechz.com

ISSN: 2455-5452

Keywords: Absent; Inferior vena cava; Venous thrombosis

\author{
Case Report
}

\section{Absent Inferior Vena Cava with Recurrent Deep Venous Thrombosis}

\section{Introduction}

Deep venous thrombosis (DVT) is relevant because of its high frequency and morbidity/ mortality rates. Its prevalence in the western population is estimated to be 1:1,000 individuals per year [1$3]$. The prevalence varies according to age, being 10 times lower in 20-40 years old individuals than in older age groups [2,3].

In young patients, its etiology is frequently associated with risk factors like congenital and acquired thrombophilia, autoimmune diseases, pregnancy, puerperuim, use of contraceptive pills, neoplasms, prolong immobilization and trauma.

The increasing use of CT angiography and magnetic resonant imaging (MRI) has allowed physician to identify more frequently the presence of IVC malformations associated with DVT of lower limbs $[1,4,5]$. Some studies report some type of IVC anomaly in approximately $5 \%$ of young patients, which suggest that this condition is a new risk factor for DVT $[1,6]$.

The prevalence of IVC anomaly in the general population is estimated to be $0.07-8.7 \%$ [1,7]. Such conditions may be associated with vague and unspecific symptoms or, in many cases may be completely asymptomatic.

In most studies, the most common anomaly of IVC is hypoplasia of prerenal and renal segments, followed by hypolasia of post renal segment and IVC duplicity [5]. In such cases the first episode of DVT occurs before 30 year of age, with similar incidence between male and females [5].

This paper describes a case with congenital absent of IVC with recurrent DVT.

\section{Case Report}

24 years-old Kurdish policeman presented with sudden sever pain of the left calf associated with significant swelling and color change. Pain increased gradually until he was unable to walk without support. After thorough examination and performing Doppler ultrasonography of the lower limbs diagnosis of DVT was made in which thrombosis extended from left common iliac vein, external iliac vein, internal iliac vein, common femoral vein, popliteal vein, great saphenous vein and small saphenous vein. Contrast enhanced $\mathrm{CT}$ of abdomen and pelvis (Figure 1a and $1 \mathrm{~b}$ ) revealed absent IVC, blood drained from iliac veins through lumber veins to Azygos vein and from it to superior vena cava. Associated with superficial subcutaneous collateral formations mostly on the right side and sever varicose vein formations in the abdomen, both in peritoneal and retroperitoneal areas.

The patient was admitted to hospital, treated by low molecular weight heparin [enoxaparin] and oral anticoagulation (warfarin). Warfarin was continued for 6 months and international normalized ratio (INR) maintained between 2-3. At the end of the treatment the patient still had mild ankle edema and almost complete venous recanalization, confirmed by Doppler ultrasonography.

Investigations to exclude thrombophilia were performed by dosing antithrombin, homocysteine, protein $\mathrm{C}$ and $\mathrm{S}$, factor $\mathrm{V}$ of leiden and prothrombin mutation, the results all were negative. The patient denied any previous history of thrombosis. There was no family history of thrombosis.

Six months after stopping the anticoagulation the patient developed DVT for the second time but this time of the right side. Doppler ultrasonography of the right lower limb show thrombosis extended from right common iliac vein, internal iliac vein, external iliac vein common femoral and popliteal vein. Because of the recurrence of thrombosis for the second time so the decision to continue oral anticoagulation for life was made.

\section{Discussion}

Abnormalities of IVC and its tributaries are rare $[1,2,4,8]$.

Different types of these abnormalities were recorded, to date reached 15 types, and the most common ones are double IVC, complete agenesis of the IVC, left IVC and Azygos continuation $[1,4,7,9]$. 


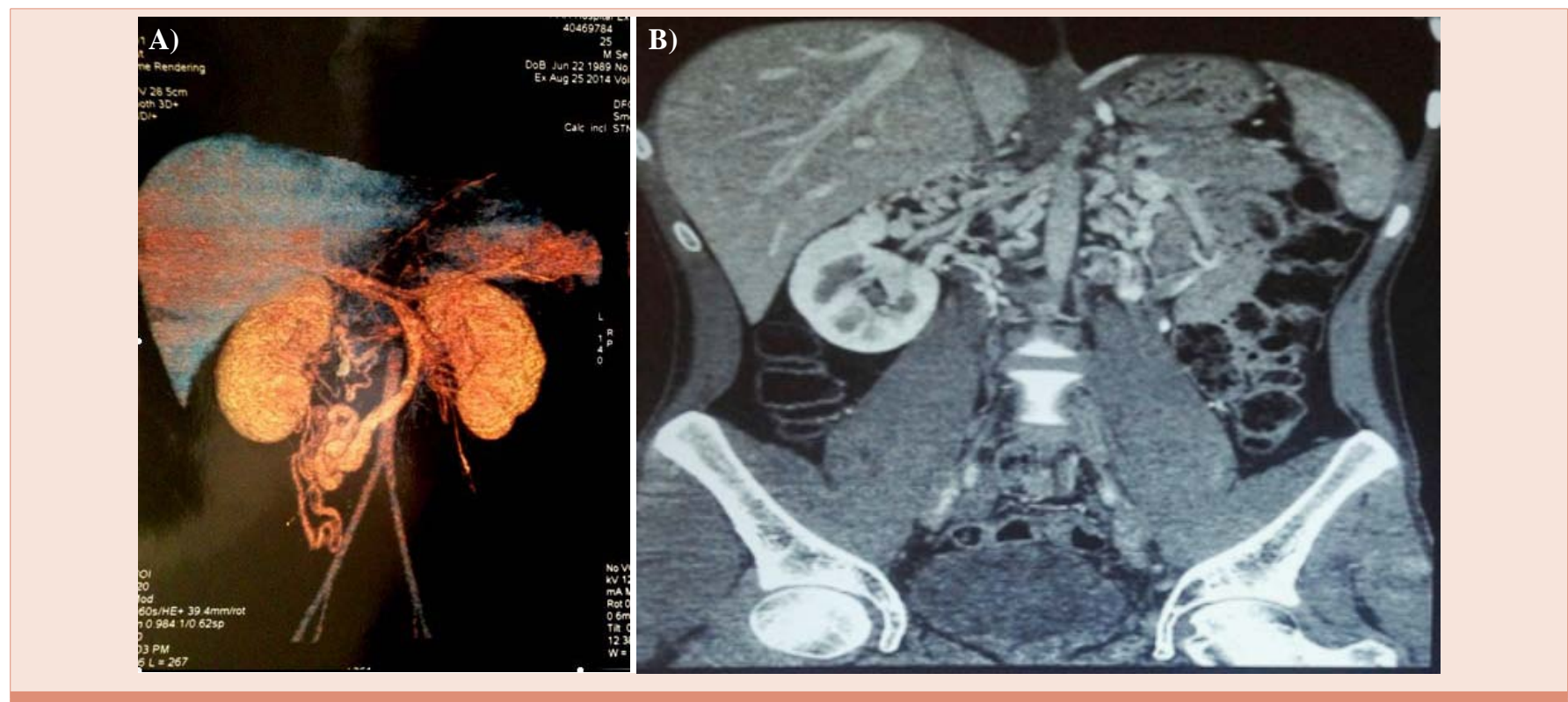

Figure 1: Coronal reconstruction of contrast CT angiography showing absence of IVC, the blood flow drained from iliac veins through lumber vein to azygos vein and from it to superior vena cava.

The etiology of IVC agenesis is controversial in literature. One of the suggestions put the possibility of thrombosis in the perinatal period as an origin for its disappearance; hence no embryological abnormalities are seen $[1,3,9]$. IVC agenesis or hypoplasia may be accompanied by other congenital abnormalities like splenic anomalies, pulmonary dysgenesis, intestinal rotations, renal agenesis and dextrocardia $[1,3,4,9,10]$.

Patients with IVC anomalies are prone to DVT due to venous stasis of the lower limbs $[1,4]$.

Echo color Doppler (ECD) allows physicians to easily detect abnormalities in lower limb veins in terms of morphological and functional impairments. Thus, ECD has become the gold standard method to evaluate the lower limb venous system, reaching sensitivity and specificity as high as $96 \%$ and $99 \%$, respectively, as compared with invasive phlebography assessment $[13,14]$. New methods were developed to better reporting of venous abnormality in the lower limbs, involving 3D imaging, the software may soon enter clinical practice in order to assist physicians in venous ECD of lower limb reporting [15].

Improvement in image qualities and increasing use of diagnostic tools lead to frequent detection of asymptomatic anatomical variations and IVC anomalies [4]. The best imaging methods are CT angiography and MRI, but the diagnosis is difficult when use ultrasonography alone $[3,4,6,11,12]$.

The most appropriate treatment in such cases is anticoagulation for at least 6 months, usually begin with low molecular heparins especially enoxaparin although some advocate bemiparin use because several studies demonstrated its safety and efficacy, while cost analyses show the economic benefits of bemiparin treatment as compared to other heparins [16].
The possibility of recurrence is high when anticoagulation is discontinued before this period [5].

\section{Conclusion}

Patients with DVT which predisposed by absent of IVC are significantly younger than those with idiopathic DVT of the lower limbs. The DVT is related to venous stasis, may be bilateral in $50 \%$ of cases. Besides there is high index of thrombosis recurrence because of inadequate venous return.

Surgical intervention is rarely indicated. Anticoagulation is the ideal treatment. There is no consensus about the duration of anticoagulation, some authors recommend life-long treatment even when thrombophilia screen is negative $[1,3,7]$.

Finally, any young patient presented with DVT without obvious predisposing factors should undergo investigation to exclude IVC anomalies.

\section{References}

1. Cho BC, Choi HJ, Kang SM, Chang J, Lee SM, et al (2004) Congenital absence of inferior vena cava as a rare cause of pulmonary thromboembolism. Yonsei Med J 45: 947-951.

2. Milani C, Constantinou M, Berz D, Butera JN, Colvin GA (2008) Left sided inferior vena cava duplication and venous thromboembolism: case report and review of literature. J Hematol Oncol 1: 24-27.

3. Iqbal J, Nagaraju E (2008) Congenital absence of inferior vena cava and thrombosis: a case report. J Med Case Rep 2: 46-49.

4. Suh HJ, Kim WT, Kim MY, et al. (2008) Combined anomaly of the right hepatic lobe agenesis and absence of the inferior vena cava: a case report. Koren J Radiol 9: s61-64.

5. García-Fuster MJ, Forner MJ, Flor-Lorente B (2006) Inferior vena cava malformation and deep venous thrombosis. Rev Esp Cardiol 59: 171-175.

6. Gayer G1, Luboshitz J, Hertz M, Zissin R, Thaler M, et al.( 2003) Congenital 
anomalies of the inferior vena cava revealed on $\mathrm{CT}$ in patients with deep vein thrombosis. AJR Am J Roentgenol 180: 729-732.

7. Obernosterer A, Aschauer M, Schnedl W, Lipp RW (2002) Anomalies of the inferior vena cava in patients with iliac venous thrombosis. Ann Intern Med 136: 37-41.

8. Yigit $\mathrm{H}$, Yagmurlu, Yigit $\mathrm{N}$ (2006) Low back pain as the initial symptom of inferior vena cava agenesis. AJNR Am J Neuroradiol 27: 593-596.

9. Bass JE, Redwine MD, Kramer LA (1999) Absence of the infrarenal inferior vena cava with preservation of the suprarenal segment as revealed by CT and MR Venography. AJR Am J Roentgenol 172: 1610-1612.

10. Atmatzidis K1, Papaziogas B, Pavlidis T, Paraskevas G, Mirelis C, et al (2006) Surgical images: soft tissue. Recurrent deep vein thrombosis caused by hipoplasia of the inferior vena cava. Can J Surg 49: 285 .

11. Gay SB, Armistead JP, Weber ME (1991) Left infrarenal region: anatomic variants, pathologic conditions, and diagnostic pitfalls. Radiographics 11 $549-570$.
12. Onzi RR, Costa LF, Angnes RF (2007) Malformação de veia cava inferior e trombose venosa profunda: fator de risco de trombose venosa em jovens. J Vasc Bras 6: 186-189.

13. Baker SR, Burnand KG, Sommerville KM, Thomas ML, Wilson NM, et al. (1993) Comparison of venous reflux assessed by duplex scanning and descending phlebography in chronic venous disease. Lancet 341: 400-403.

14. Eichlisberger R, Frauchiger B, Jäger K (1991) Assessment of the leg veins using duplex ultrasonography. Ther Umsch 48: 697-707.

15. Galeandro AI, Scicchitano P, Zito A, Galeandro C, Gesualdo M, et al. (2014) A three-dimensional electronic report of a venous echo color Doppler of the lower limbs: MEVeC®. Vasc Health Risk Manag 10: 549-555.

16. Ciccone MM, Cortese F, Corbo F, Corrales NE, Al-Momen AK, et al. (2014) Bemiparin, an effective and safe low molecular weight heparin: A review. Vascul Pharmacol 62: 32-37. 